\title{
Three Dimensional Images of the Kamchatka-Pacific Plate Cusp
}

\author{
Jonathan M. Lees ${ }^{1}$, John VanDecar ${ }^{2}$, Evgenii Gordeev ${ }^{3}$, Alexei Ozerov ${ }^{3}$, \\ Mark Brandon ${ }^{4}$, Jeff Park ${ }^{4}$, Vadim Levin ${ }^{5}$
}

First arrivals of seismic waves were recorded along the Kamchatka arc using broadband seismic stations deployed for one year in 1998-1999. Cross correlation methods were used from a high resolution data set for tomographic inversion of body waves. The P-wave teleseismic tomography shows evidence of slab shoaling along the northern terminus of the Kamchatka subduction zone. Tomographic anomalies corroborate trends in seismicity, geochemistry, heat flow, shear wave splitting, and surface wave inversions. Thermal ablation via contact with asthenosphere, under the proper conditions, is offered as a possible explanation of the observed shoaling of the Kamchatka slab edge.

\section{INTRODUCTION}

The Aleutian-Kamchatka corner is a trench-transform junction that forms a cusp on the boundary between the Pacific and North American plates. Unique to this junction is Earth's most extreme example of exposure of an arc cusp where the side-edge of a subducting plate is heated by mantle flow. In this paper we present results from a tomographic study using teleseismic arrivals at an array of seismic stations deployed temporarily in Kamchatka during 1998-1999. Evidence for this fact is manifest: seismicity shallows to the north [Gorbatov et al., 1997], teleseismic tomography shows a deepening of high velocity dipping to the southwest [Lees, 2000], high heat flow in the Komandorsky Basin [Baranov

\footnotetext{
${ }^{1}$ University of North Carolina, Chapel Hill, Department of Geological Sciences, Chapel Hill, North Carolina, USA

${ }^{2}$ Department of Terrestrial Magnetism, Carnegie Institution of Washington, Washington, DC, USA

${ }^{3}$ Institute of Volcanology and Seismology (IVS), PetropavlovskKamchatsky, Russia

${ }^{4}$ Yale University, New Haven, Connecticut, USA

${ }^{5}$ Department of Geological Sciences, Rutgers University, Piscataway, New Jersey, USA
}

Volcanism and Subduction: The Kamchatka Region Geophysical Monograph Series 172

Copyright 2007 by the American Geophysical Union. 10.1029/172GM06 et al., 1991], and shear wave splitting indicates trench-parallel sub-slab orientations along the Kamchatka Arc changing to NW trending orientation north of the Aleutian-Kamchatka Junction [Peyton et al., 2001]. Yogodzinski et al. (2001) used the idea of a torn slab and exposed oceanic lithosphere to further explain the presence of calc-alkaline volcanics [Defant and Drummond, 1990; Defant and Kepzhinskas, 2001; Hochstaedter et al., 1994] just north of the junction, providing a new model for the presence of Adakites found in the central and western Aleutians. Detailed descriptions of Kamchatka tectonics can be found in numerous publications and will not be repeated here [Gaedicke et al., 2000; Geist and Scholl, 1994; Nokleberg et al., 2001; Park et al., 2002; Seliverstov, 1998].

The question of how the exposed edge of a torn slab interacts with the surrounding mantle has profound worldwide implications for geochemistry of mantle asthenosphere and eruptive magmas and geodynamics of flow in the upper mantle. There is evidence that tears of the kind observed in Kamchatka are ubiquitous in the Pacific Rim. Kirby et al. [1996] noted pointedly in their seminal paper on subduction zone seismicity and thermal models that arc cusps around the western Pacific all have shoaling seismic zones towards the cusps. If exposed slab is constantly ablating and being absorbed in the upper mantle we will have to reevaluate our notions on the chemical makeup of the upper mantle [Lees, 2000; Yogodzinski et al., 2001]. Fluid flow models of 
the upper mantle and models of corner flow will have to be adjusted significantly if stresses associated with tear model flow are correct.

At nearly every cusp around the Pacific Rim there is an observed shoaling of seismicity cusp-ward from the deep subducted plates [Kirby et al., 1996]. Shoaling seismicity is especially pronounced at the Kamchatka-Aleutian junction where the Kamchatka arc terminates against the Bering Fault of the western Aleutians. While in some localities the shoaling seismicity may be attributed to the youth of the subducting lithosphere, in Kamchatka the Cretaceous age of the lithosphere precludes this interpretation. Rather, the old subducting lithosphere requires a completely different interpretation to explain the absence of seismicity in the Kamchatka-Aleutian cusp.

\section{THE EDGE OF A PLATE}

The main point of this paper is to present results of three dimensional imaging of the Kamchatka plate as it subducts in the western Pacific. The images were derived via tomographic inversion of P-wave arrivals from teleseismic body waves and show a clear edge of the northern extent of the subducting Pacific plate, confirming earlier results which included analysis of slab events and global surface wave inversion. The P-wave arrivals recorded at 15 broadband stations deployed in 1998-1999, however, offer the best chance so far of imaging the deep part of the slab with clarity and fidelity.

Earthquakes in the subducting Kamchatka slab extend from the surface where the Pacific plate collides with Eurasia down to $600 \mathrm{~km}$ depth. Events form a clear Wadati-Benioff zone that dips consistently at about 50 degrees to the west. By plotting events in cross section one can determine a general trend and contour the top of seismicity to be used as a proxy for the extent of the slab in the mantle. Contours of seismicity appear to shoal towards the north where the Aleutian arc terminates at the Kamchatka Peninsula. At the apex of the seismicity the gradient of dip shallows in the vicinity of the Kliuchevskoi group of volcanoes. The lack of deep seismicity in the northern part of the subduction zone is a strong indication that subduction is absent in this region. The overall shape of the slab in Kamchatka, based on seismicity alone, appears to be tongue-like, with the deepest events occurring near the center of the Kamchatka-Kurile arc and shoaling north and south towards the ends.

\section{Tomography}

Earlier tomographic inversions of structure in Kamchatka consist of P-wave tomography using the large world wide catalogues suggest that there is no slab extending north of the northern terminus of seismicity as discussed above [Gorbatov et al., 1999; Gorbatov et al., 2000]. These inversions use a combined data set of arrival times extracted from regional arrays of the Geophysical Survey of Russia and travel time arrivals from global (ISC, NEIC) data bases. The presence of considerable noise in these data can be problematic for tomographic inversion. The inversion presented in our analysis is obtained independently from the global dataset, and provides much needed waveform information from the isthmus region of Kamchatka north of the KamchatkaAleutian Cusp (KAC). Our results solidify and extend the earlier tomography results and provide details. A study using surface waves (S-wave velocities) [Levin et al., 2002] shows a termination of the slab in KAC region, in agreement with the P-wave analysis presented here. Furthermore, Levin et al. [2002] speculate that the absence of high velocity S-wave anomalies north of KAC is evidence for catastrophic slab loss in the subduction zone. The P-wave results presented below also show no evidence of remnant slab fragments north of the subduction zone.

\section{Heat Flow}

Oceanic heat flow in the Kamchatka region is governed primarily by the thickness of the Pacific Plate and local extension in the Komandorsky basin [Smirnov and Sugrobov, 1982]. The Komandorsky basin, north of the Bering Islands, is the locus of relatively recent spreading ( $\sim 5 \mathrm{M}$ years) which points to an upper mantle heat source north of the Bering fault. Anomalous heat flow is also observed above the Meiji Sea Mounts, east of Kamchatka and south of the Bering Islands.

Modeling of the thermal regime of the slab, based solely on conduction, as it thrusts into the mantle shows that internal geotherms follow seismicity contours in the upper most part $(<100 \mathrm{~km})$ of the slab where the slab appears to bend to the northwest [Davaille and Lees, 2004]. Below $100 \mathrm{~km}$ depth thermal conduction alone cannot account for the reduction of observed seismicity and additional ablation, perhaps from small scale convection associated with the remnant Meiji Seamounts may account for the drastic reduction of seismicity and the curve of apparent termination of hypocenter trends to the south.

\section{Shear Wave Splitting}

Shear wave splitting using SKS seismic waves arriving in Kamchatka revealed evidence for trench parallel orientation of fast directions. This was interpreted as evidence for preferred orientation of olivine crystals deformed to align 
along the direction of mantle flow as material deforms during slab roll back. Laboratory modeling [Buttles and Olson, 1998], aimed at simulating the effect of slab roll back on shear wave splitting in the mantle, confirms observations of trench parallel polarizations in numerous subduction zones around the Pacific Rim [Russo and Silver, 1994], including Kamchatka [Peyton et al., 2001]. Recent new observations of source side anisotropy supports this view and provides definitive evidence for placing the locus of the shear wave splitting below the slab 100-400 km depth [Russo and Lees, 2005]. Evidence for flow beyond the northern terminus of slab as imaged here is much more sparse but the few points imaged by Peyton et al. [2001] seem to agree, more or less, with the idea that there is a component of flow around the edge of the slab in the north. Local S-wave splitting in the mantle wedge indicated that the fast polarization rotates around near the cusp, suggesting mantle flow distortion above the slab near its edge [Levin et al., 2004]. While the P-wave velocity perturbation images presented in this paper do not show specific evidence of this around the edge flow, the lack of significant high velocity anomalies in the north corroborates the notion that warm material is flowing around the Kamchatka slab to the north.

\section{Geochemistry}

The geochemistry of the volcanic rocks in the northern region of the Kamchatka Arc exhibits a unique pattern that supports the termination model of the Pacific plate in the vicinity of the Kliuchevskoi group of volcanoes [Portnyagin et al., 2005; Yogodzinski et al., 2001]. Strong, lateral zonation of older, oceanic-type, volcanic centers in the north versus younger, arc-type, active volcanoes in the south indicates an abrupt change in tectonics bounding the KAC [Portnyagin et al., 2005]. A more detailed, fine line demarcation is suggested by models of Yogodzinski et al. [2001] where the presence of adakitic volcanics are found north of the junction of Kliuchevskoi-Sheveluch axis, but not to the south. The model suggests that slab melts are derived from ablated slab as the Pacific plate plunges into the mantle: the exposed edge provides a source for slab to contaminate rising melts and significantly modify the erupted magmas.

\section{INSTRUMENTATION AND ARRAY DESCRIPTION}

The seismic experiment was designed to span the extent of Kamchatka targeting the intersection of the AleutianKamchatka junction. The installation included 15 broadband PASSCAL instruments equipped with Guralp CMG3T sensors (120 s period) deployed for a period of one year. The full complement of seismic stations was active and recording reliably for a period of about 9 months. Details of the installation can be found in earlier publications [Lees et al., 2000; Peyton et al., 2001]. A map of the seismic station locations is provided in Figure 1 where the names of stations are indicated for reference. 107 teleseismic and regional events with more than 10 stations recording were recorded during the time period of the deployment and the source locations for events at angular distances less than 100 degrees are presented in Figure 2 (one event with core-phase arrivals was also used in the analysis). There is reasonably good coverage of events except for gaps in the south east.

An example of a particularly good seismic record is illustrated in Figure 3. This M6.5 event was recorded on April 8, 13:10 GMT and registered a focal depth of $565 \mathrm{~km}$. The waveforms have been re-aligned so that the predicted first arrival is the same for all. The predicted first arrivals are

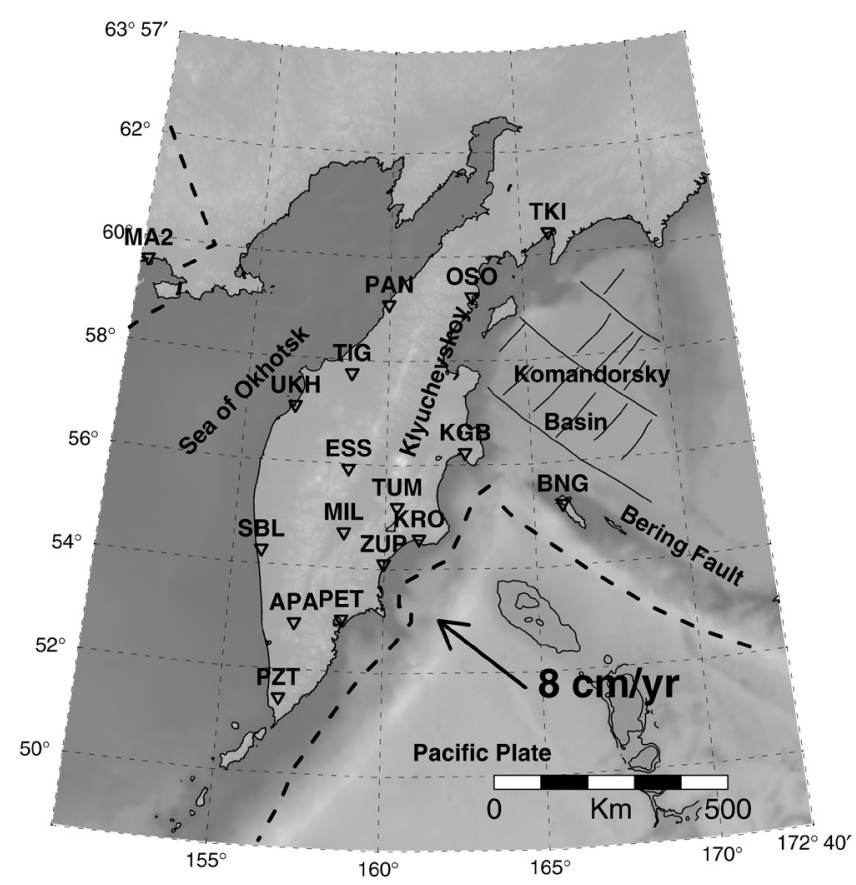

Figure 1. Map of the Kamchatka-Aleutian region. Showing station locations of the SEKS (Side Edge of Kamchatka Slab) array (red) and permanent GSN stations (MA2, PET) in the region. Stations KGB, KRO, ZUP, PET and PZT are located along the volcanic arc. Station BNG was located on Bering Island. The central Kamchatka depression is located between the Sredeny range and coastal volcanic arc. The Kliuchevskoi volcanic complex is situated in the central Kamchatka depression offset to the northwest from the line of arc volcanoes to the south. The plate boundary between the Pacific and Eurasian Plates is presented as a thick reddish line. Contours along topographic highs in the ocean southeast of station KRO are the oceanic Meiji Seamounts. Magnetic anomaly lineations in the Komandorsky Basin are shown where seafloor spreading has occurred in the last 5 My [Moore et al., 1992]. 


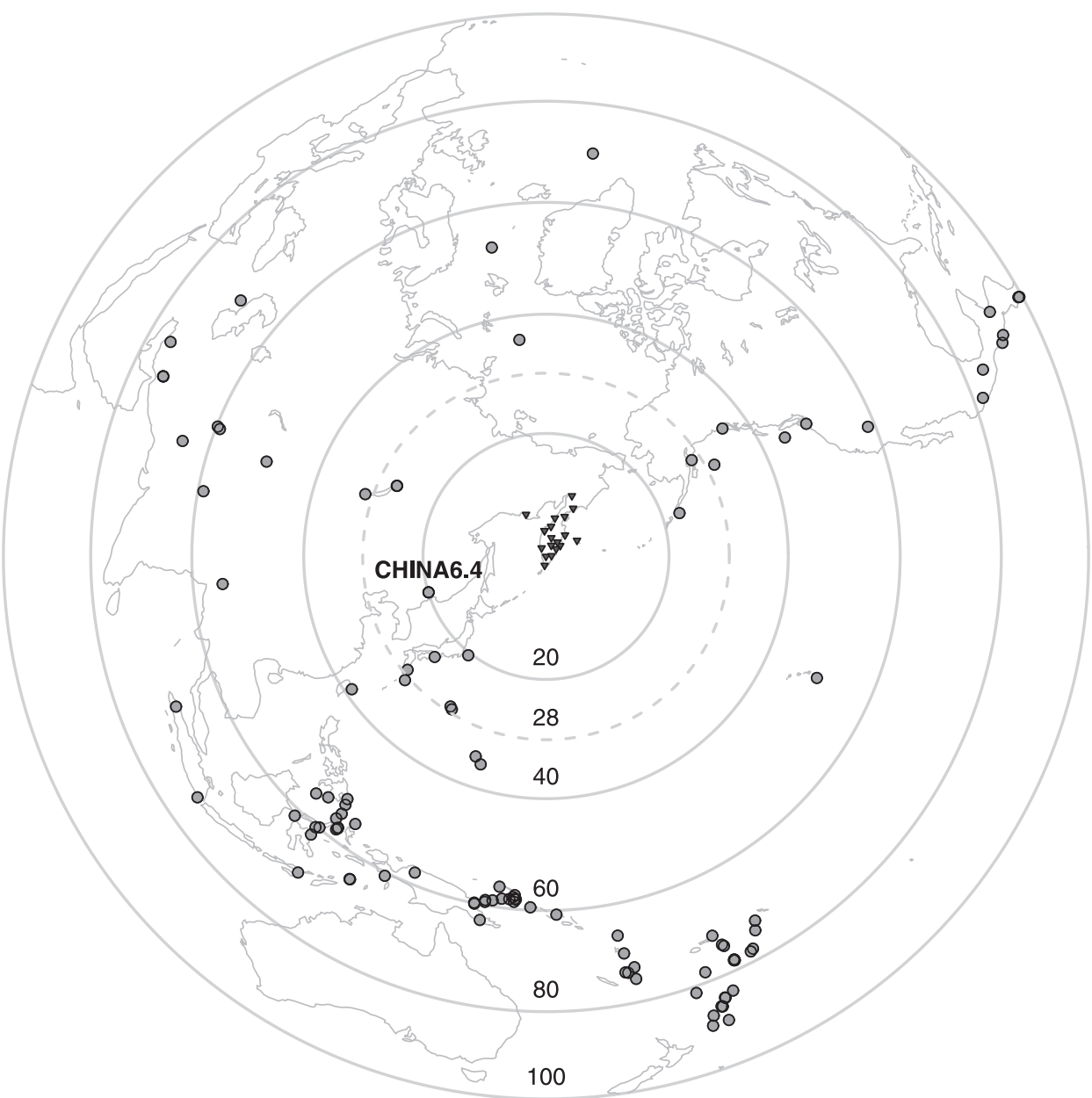

Figure 2. Equal-area projection of the world with Kamchatka at the center. SEKS array is represented as small triangles on the Kamchatka Peninsula. Small circles are earthquake hypocenters for events recorded in 1998-1999 by the SEKS array in Kamchatka. Of 107 events identified, 102 were used in the tomographic inversion. Events with distance less than $30^{\circ}$ were excluded except for the notable event marked CHINA64 which occurred on April 8, 1999 at 1:10 GMT. This event was located at $565 \mathrm{~km}$ depth.

calculated from a one-dimensional spherically symmetric layered model. The fact that some arrivals come in late and others early indicated that the 1-D model does not adequately explain the travel times and a three-dimensional model is required to account for the discrepancy. The difference between the predicted and observed arrival at each station is called the residual and is used in the tomographic inversions presented in this paper. One especially intriguing observation from this seismic record is the later arrival of the high frequency signals at stations KRO and KGB.

While the analysis of dispersive waves is beyond the scope of this paper, the delay of high frequency waves from this event may be caused by internal structure in the slab that causes waveguide dispersion [Abers, 2000]. We note that in the example shown in Figure 3 stations PET and ZUP do not show appreciable evidence of this observation. We have searched for further evidence of waveguides propagating up the slab, in numerous events recorded on the broadband array, but we have not been able to identify this phenomenon independently. It may be that the waveguide modes are excited only in specific circumstances when the slab geometry, source radiation and receiver array are oriented appropriately. Path effects and shallow heterogeneity in the vicinity of the $\mathrm{KAC}$ may also play a roll in producing a dispersive wave.

\section{TOMOGRAPHIC MODELING}

To derive a three dimensional model of the deep structure below Kamchatka we extracted teleseismic events from the continuous recording and determined P-wave arrival times at first by manual picking and later these were refined by 
cross correlation [VanDecar and Crosson, 1990]. The cross correlation method reduces biases associated with human picking and provides very precise estimates of arrival times used in the inversion. The final data set included 102 events with at least 6 well recorded first arrivals (with most events recorded by 12 or more stations), providing 1161 total raypaths. Relative arrival times were derived using cross-correlation and residual travel times were then inverted for $\mathrm{P}$-wave velocity variations in the subduction zone. A plot of the distribution of events from the global catalogue is presented in Figure 2. The azimuthal coverage is reasonable although notable gaps exist.

At each station residuals are determined by estimating the predicted versus observed arrival times. These are presented graphically via residual spheres, Figure 4. Arrivals coming up the slab from the south-west at stations KGB, KRO, and ZUP, show a clear negative trend, indicating the presence of the strong, high velocity of the subducting slab. Note that at station KGB several arrivals from the north east show the opposite trend. By contrast, arrivals in the northern stations
(TKI, OSO, PAN, TIG, and UKH) are either mixed or tend to have positive anomalies. This pattern strongly suggests that structure in the northern part of Kamchatka is significantly different from that in the south. The first cut interpretation of the residual plots, prior to tomographic analysis, shows that P-wave arrivals recorded during this experiment strongly suggest that the edge of the slab resides near the boundary between station KGB and TUM. These travel time residuals comprise the basic data that are used in the tomographic inversion, described next.

Our tomographic models are derived by inverting the relative arrival times for smooth $3 \mathrm{D}$ perturbations in the seismic velocity beneath the array. The Earth's interior was parameterized (Figure 5) at 90576 nodes: 37 in the radial direction, 48 in latitude and 51 in longitude, with the velocity (in practice, slowness or $1 /$ velocity) between nodes constrained by splines under tension. Raypaths were determined via a shooting method that traces rays from distant events that arrive teleseismically in Kamchatka. Within the region near Kamchatka where the model is perturbed, rays

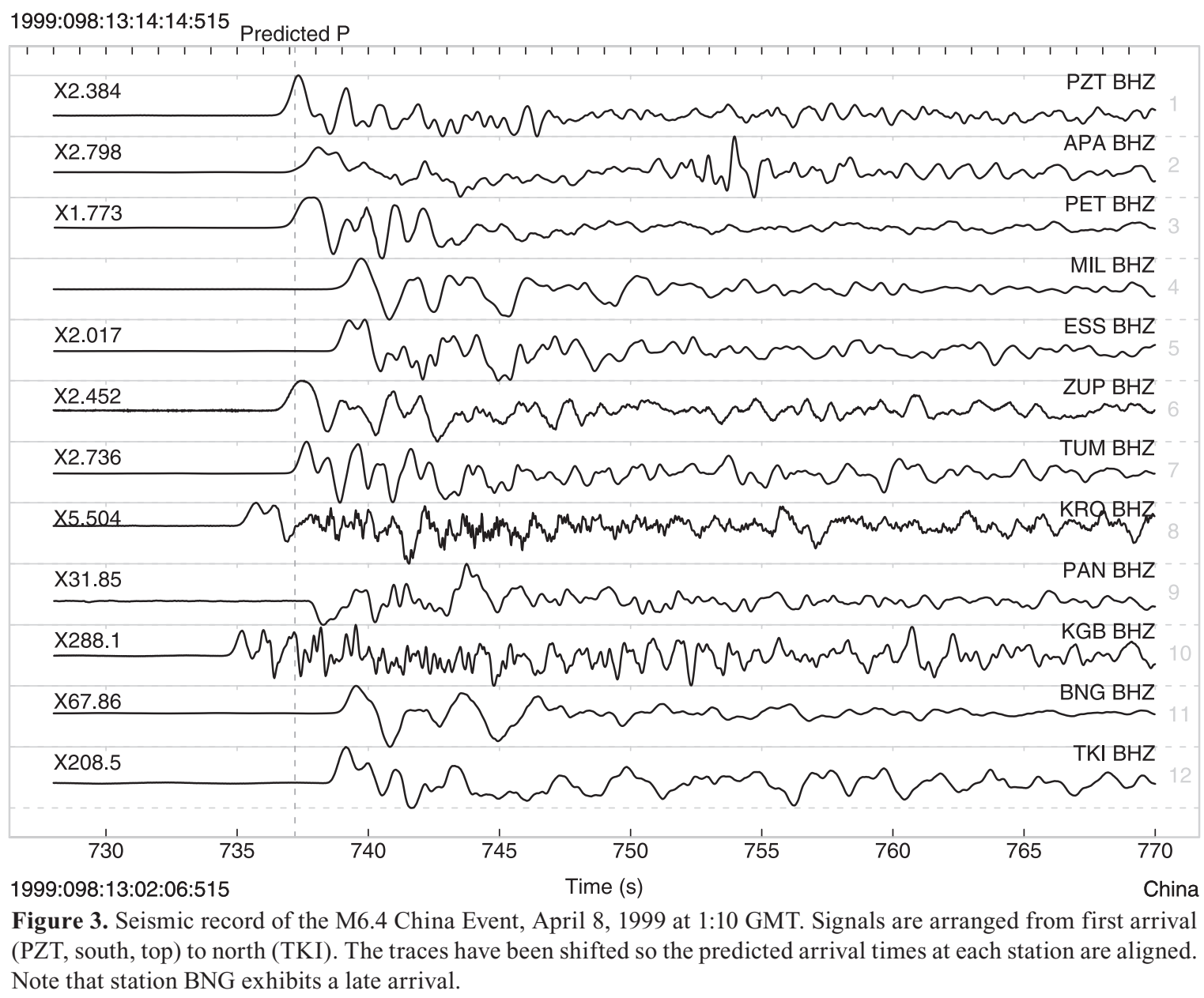




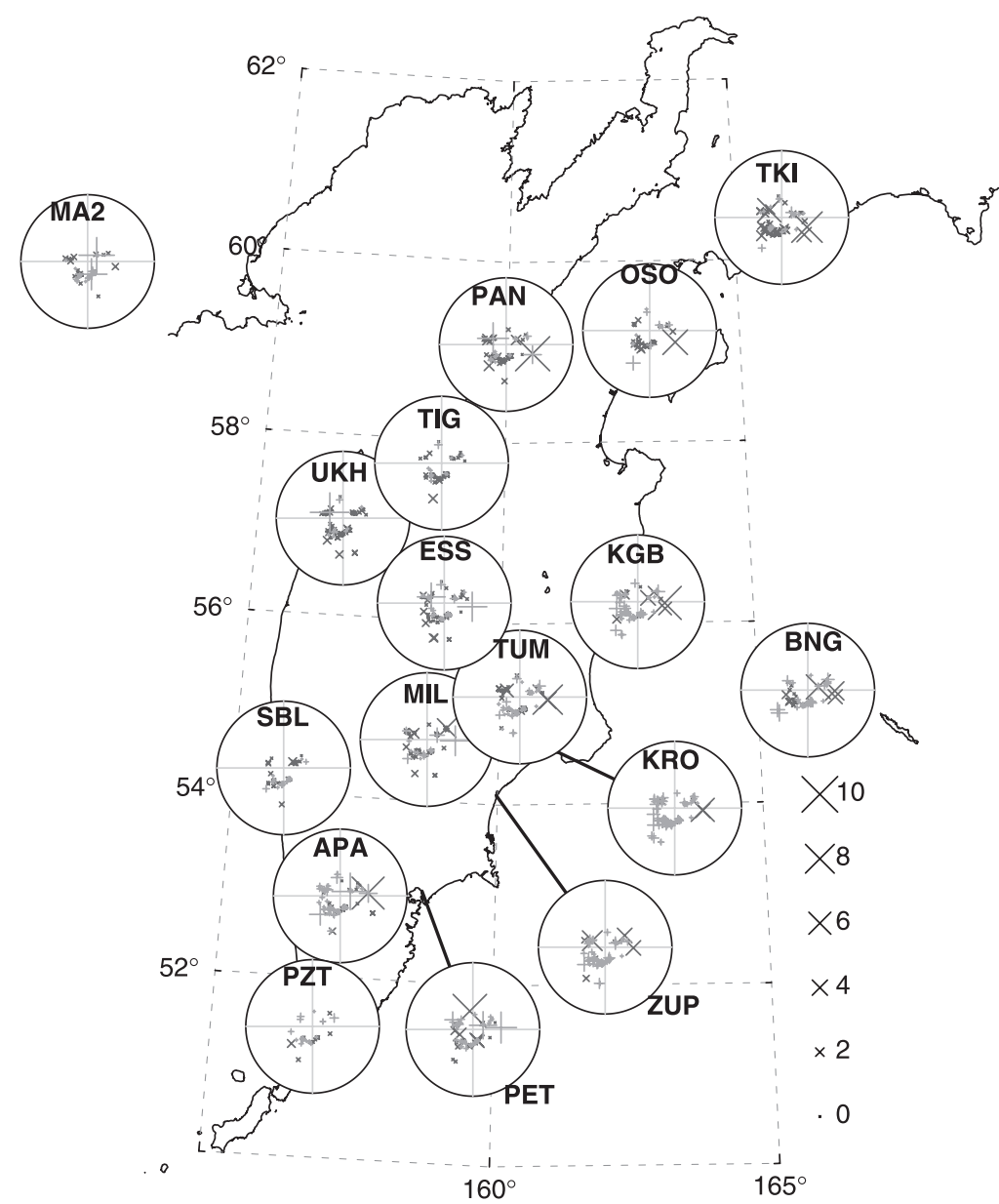

Figure 4. Residual spheres for the data arriving at SEKS stations in 1998-1999. Each sphere represents an equal area projection of incoming rays at each station. Points are plotted at the back azimuth and incident angle of each datum. Darker $\mathrm{X}$-marks and lighter +-marks are positive and negative residuals respectively. Marks are scaled by size in seconds.

bend according to the 3D models; outside this region, the rays follow a radially symmetric 1D Earth model (IASP91 [Kennett and Engdahl, 1991]). Once raypaths and residuals are determined, a matrix is inverted and perturbations from the $1 \mathrm{D}$ model are plotted showing the $3 \mathrm{D}$ variations in velocity required to explain the residual travel times. Apriori smoothness constraints are invoked by requiring first and second spatial derivatives to be small, which reduces large fluctuations when noise is present. Each inversion involves thousands of iterations and $>95 \%$ residual reduction is typically achieved. Linear and non-linear inversions are explored as well as resolution tests using synthetic models. We confidence in our model results and details of our inversion procedure can be found in VanDecar et al. [2003].

The tomographic inversion (Plates 1-3) is presented as a series of horizontal, vertical and rendered representations of the full three-dimensional perturbation model. The first order interpretation shows a clear signature of the subducting slab as a high velocity anomaly inclined at approximately 50 degrees plunging to the north-west in agreement with the seismicity. Noteworthy is the apparent slab shoaling towards the northern terminus of the subduction zone in Kamchatka where the Aleutian Islands intersect with the Kamchatka Arc. This is seen as varying anomalies trending from north to south in the descending horizontal slices (Plate 1), as well as in differences in the presence of high velocities (blue) in vertical slices $X$ versus Z (Plate 2). Since the tomographic model is derived from teleseismic arrivals it is not biased by local data (seismicity) in the subducting slab. The fact that the seismicity shallows in the same way that the tomographic model shoals corroborates the assertion that the slab varies considerably as it approaches its northern terminus. Either the slab has heated up to the extent that it can no longer sustain the stresses required for seismicity, or it simply does not exist. These results corroborate and are independent of surface wave studies that image S-wave propagation in Kamchatka [Levin et al., 2002]. 


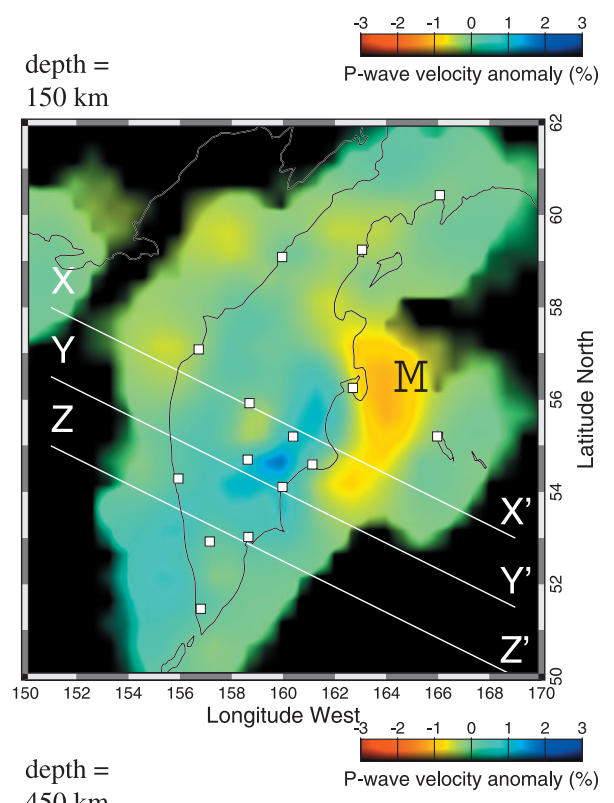

$450 \mathrm{~km}$
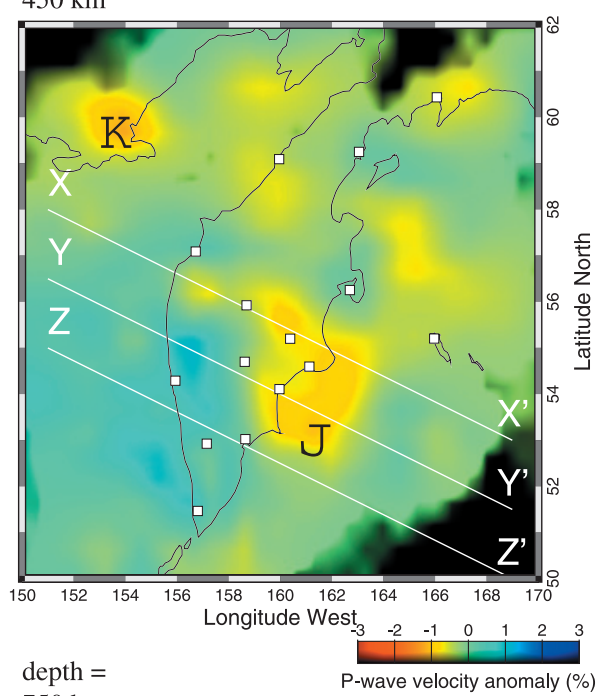

$750 \mathrm{~km}$

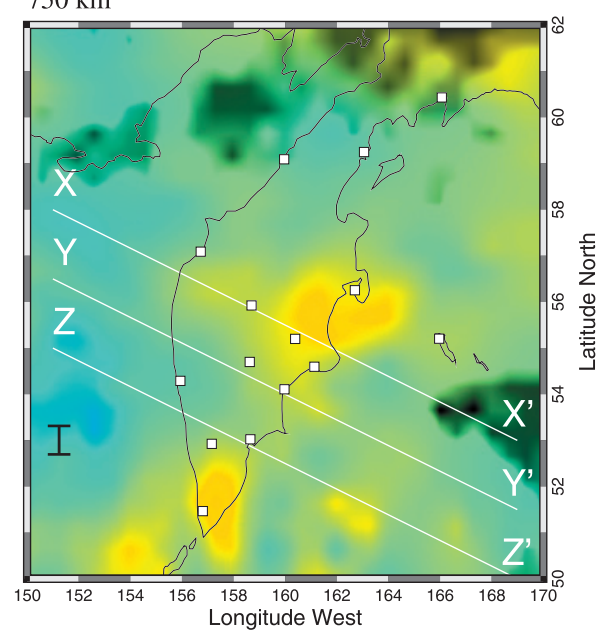

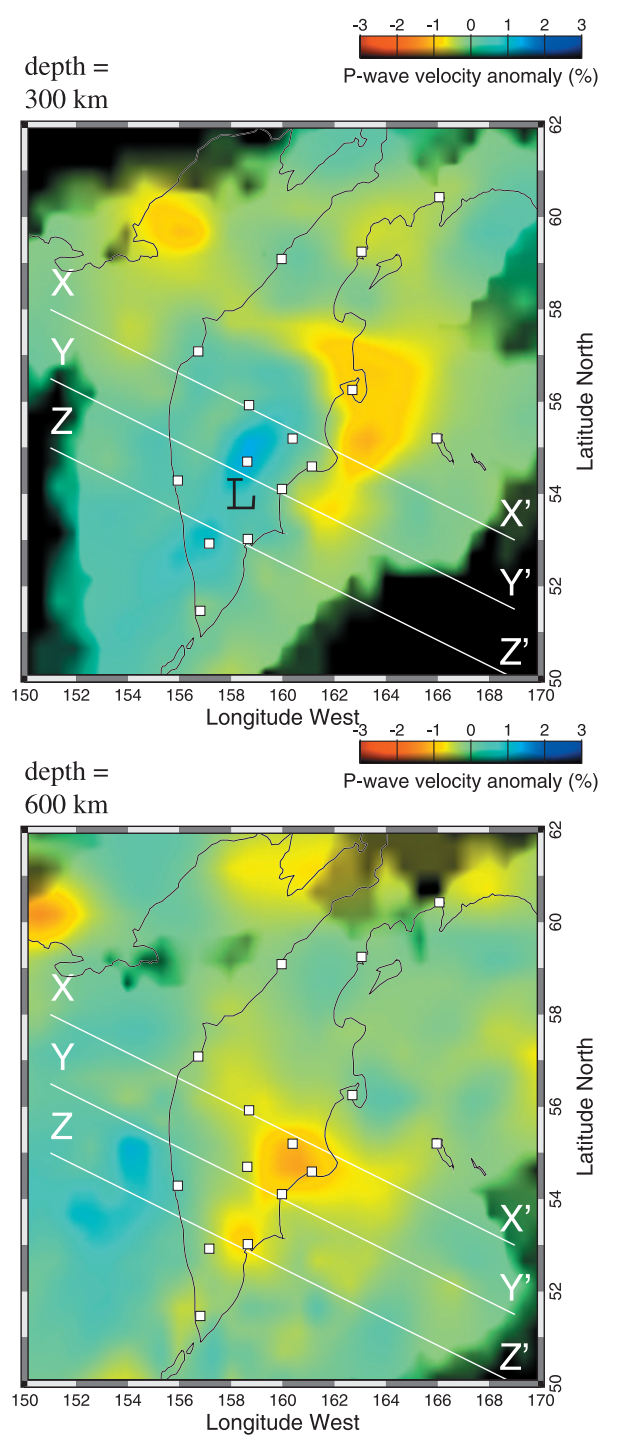

Plate 1. Horizontal slices through the tomographic model. Slices are taken at depths 150-750 showing perturbations of the velocity to the background, one-dimensional velocity model. Color scales range from blue (fast) to red (slow) marking perturbations in the velocity inversion. All colored regions are darkened to black where ray coverage get sparse. Loci for vertical cross sections presented in Plate $2(\mathrm{X}, \mathrm{Y}, \mathrm{Z})$ are shown for reference. Points of interest discussed in the text are marked with letters (I-M). 


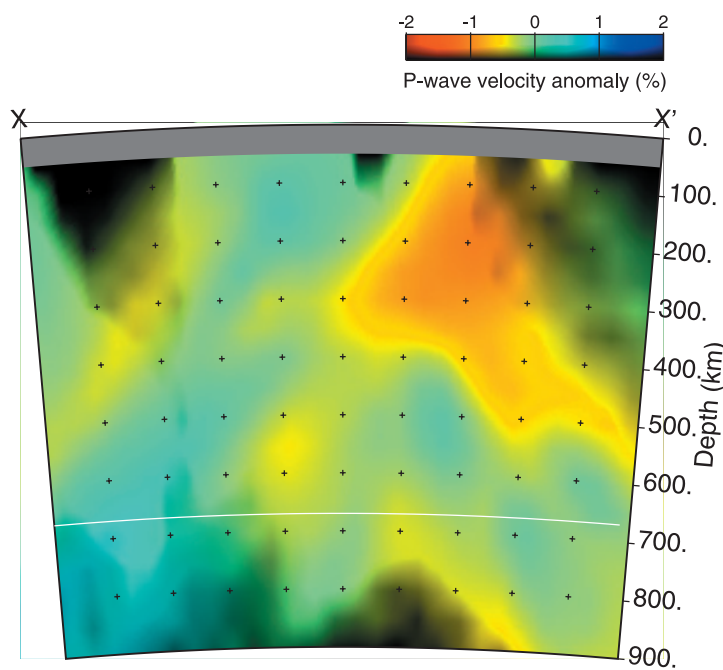

$\mathrm{X}:(58.00 \mathrm{~N}, 151.00 \mathrm{E})$

$X^{\prime}:(56.00 \mathrm{~N}, 169.00 \mathrm{E})$

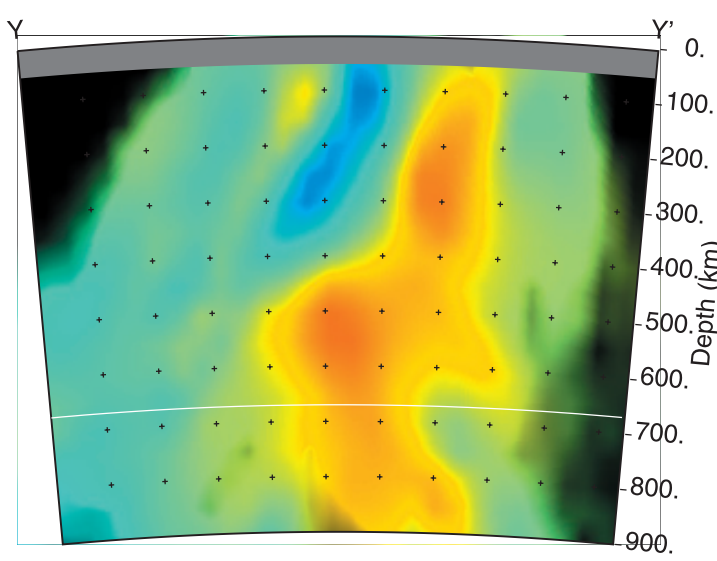

$\mathrm{Y}:(56.00 \mathrm{~N}, 151.00 \mathrm{E})$

$Y^{\prime}:(54.00 \mathrm{~N}, 169.00 \mathrm{E})$

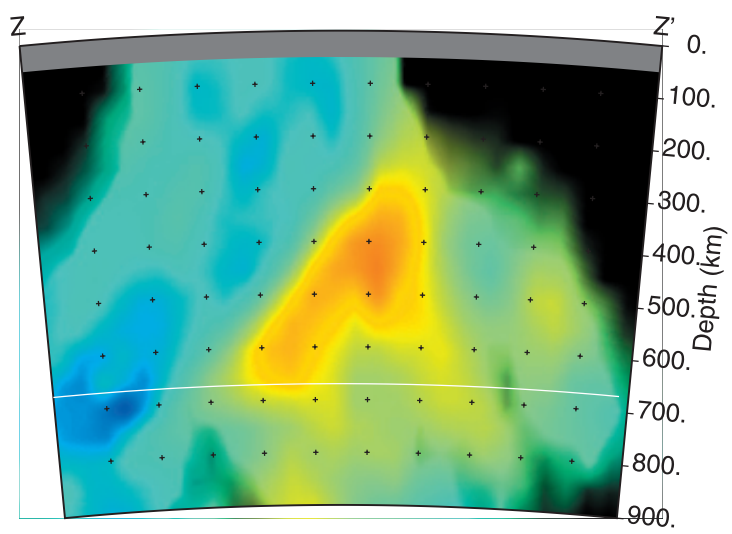

Z: ( $54.00 \mathrm{~N}, 151.00 \mathrm{E})$

Z': (52.00N, 169.00E )

\section{L2 P-wave inversion}

Plate 2. Vertical cross sectional slices through the tomographic model. Map orientation of the cross sections is shown in Plate 1.
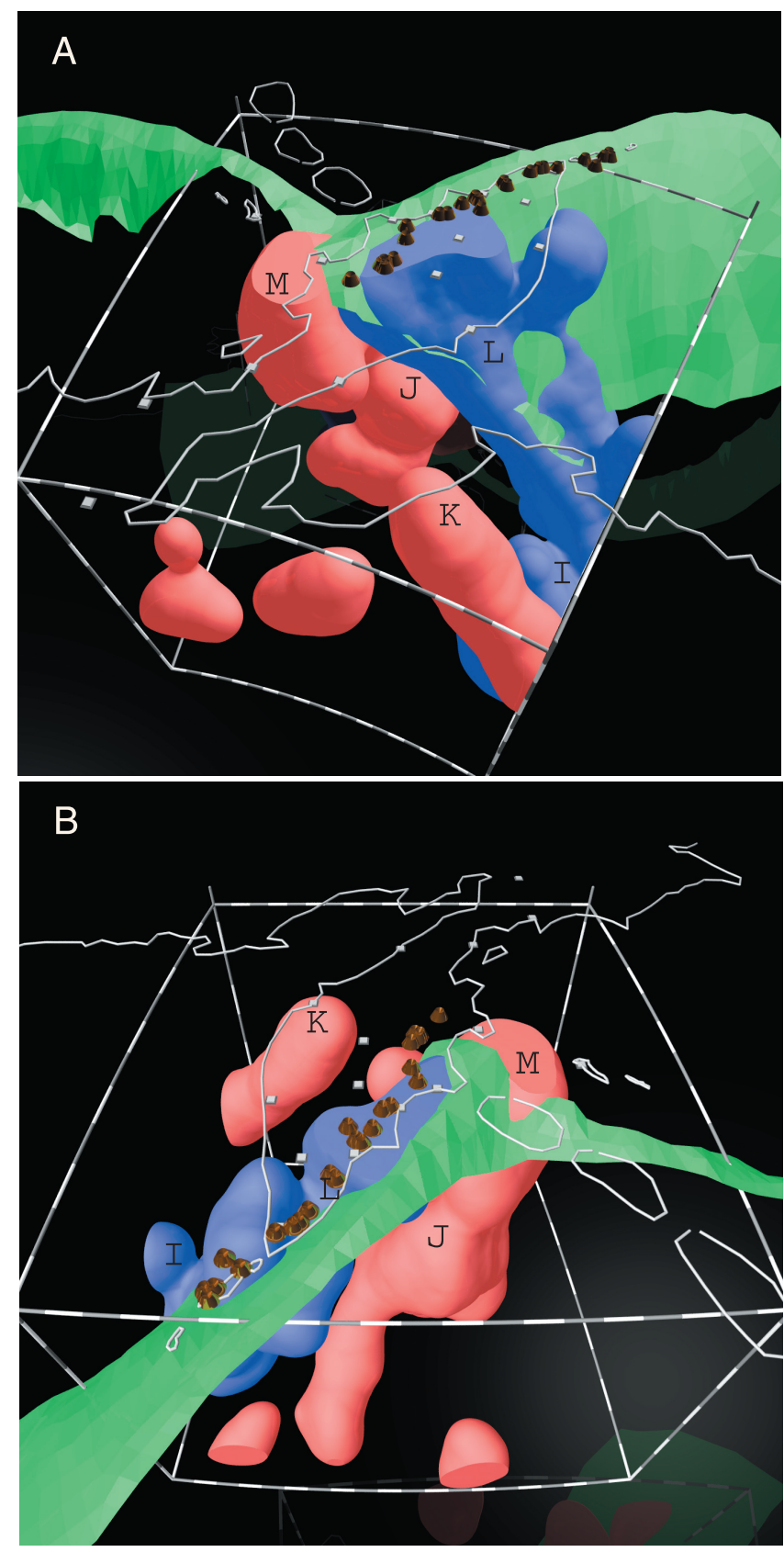

Plate 3. Tomographic image of the Kamchatka Subduction zone rendered in three-dimensions. The cut-off perturbation level is 3\% with blue regions being high velocity and red lower velocity perturbations. The slab is a clear high velocity zone approximately 100 $\mathrm{km}$ thick plunging into the upper mantle at an angle of $\sim 50^{\circ}$. The green plane represents the top of the subduction zone seismicity, contoured and rendered along with the tomographic images. Gold cones are active volcanoes along the Kamchatka arc and white squares are stations included for reference to the map in Figure 1. The bars represent length scales of $100 \mathrm{~km}$. Points of interest discussed in the text are marked with letters (I-M). 
We describe the inversion results by high-lighting important anomalies from the deepest parts of the model to the surface (Plates 1-3). (Please see the "Animated view of the tomographic inversion of Kamchatka subduction zone" on the CDROM accompanying this volume.) At $750 \mathrm{~km}$ depth the slab is not evident, but a broadened high velocity can be seen (labeled I) northwest of Kamchatka on the western side of the Sea of Okhotsk. This anomaly merges with the slab at around $600 \mathrm{~km}$ depth beneath the sea of Okhotsk. Low velocity perturbations can be seen below station KRO at this depth (labeled J). At $450 \mathrm{~km}$ depth the slab is perceived as a high velocity perturbation and a low velocity lineation can be seen in a triangle formed by stations BER, KRO and KGB (labeled L). Another low velocity anomaly is observed north of stations PAN and OSO in the northern section of Kamchatka (labeled K). The subducting slab is best observed at depths $300-150 \mathrm{~km}$. At these depths (especially $300 \mathrm{~km}$ depth) there is a noticeable signature of low velocity between BER and KGB (labeled M) where we anticipate mantle flow around the northern terminus of the slab as suggested by analyses of shear wave splitting based on teleseismic S-wave studies.

Resolution analyses of this inversion show that the horizontal resolving power is greater than vertical resolution for teleseismic tomography. In the Kamchatka inversion we suggest that the resolution is on the order of $100 \mathrm{~km}$ near the center of the model ( $300 \mathrm{~km}$ depth) where the interpretations are most important. Near the edges of the model, data coverage is poor and smearing and instability prevents us from providing a detailed interpretation.

The shoaling and diminishment of the Kamchatka slab northward appears to corroborate the hypothesis put forward by Yogodzinski et al. [2001], namely, that there exists a significant tear in the slab between the western Aleutians and northern extent of the Kamchatka Arc. Further elaboration of this model is presented via imaging by Levin et al. [2005] along the Aleutians. It may be that all slabs exhibit some form of ablation at their edges where cusps are formed on oceanic plates. Kirby et al. [1996] show seismicity around the Pacific rim in cross section and notes that at each cusp there is pronounced shoaling towards the point where arcs change direction. As a second, detailed example of this phenomenon, a cross section of seismicity at the Kurile-Japan Trench below Hokkaido shows a similar trend (see illustration in this monograph on seismicity along the Japan-Kurile-Kamchatka subduction zones). There the shoaling does not trend towards the surface as in Northern Kamchatka but rather stops much deeper in the subduction zone. We interpret this as a breach in the slab, although in this case the breach terminates at depth and slab ablation may not have a geochemical signature as observed in Kamchatka. A simple search around the Pacific Rim at other cusps (Central American Cocos plate,
Taiwan Pacific plate) confirms the observation that slabs shoal near cusps as suggested in a rough way by Kirby et al. [1996]

The absence of high velocity slab in the northern corner of the Kamchatka subduction zone suggests that the slab is either heated to the extent that seismic anomalies are considerably reduced in this region or that the slab simply does not extend into this part of the upper mantle (does not exist). If the slab does not extend into the mantle below the $\mathrm{KAC}$, then a large portion of the slab must have been ablated (or foundered?) during the subduction process. Considering the large number of slab edges across the globe, this implies that the mantle is contaminated with slab material, at least near the edges where subduction shoals and volcanism terminates. Furthermore, the slab window provides a conduit for upper mantle material to flow through the breach, which explains the patterns of shear wave splitting observed in Kamchatka. This may also provide an explanation for the westward shift of the Kliuchevskoi group of volcanoes in the northern terminus: flow around the edge deforms the slab at the northern edge, ablates it and produces the westward warp and uplift. Other mechanisms have been proposed by Park et al. [2002].

The subduction of the aseismic Meiji seamounts represents a slight twist in this simple model of slab ablation and mantle

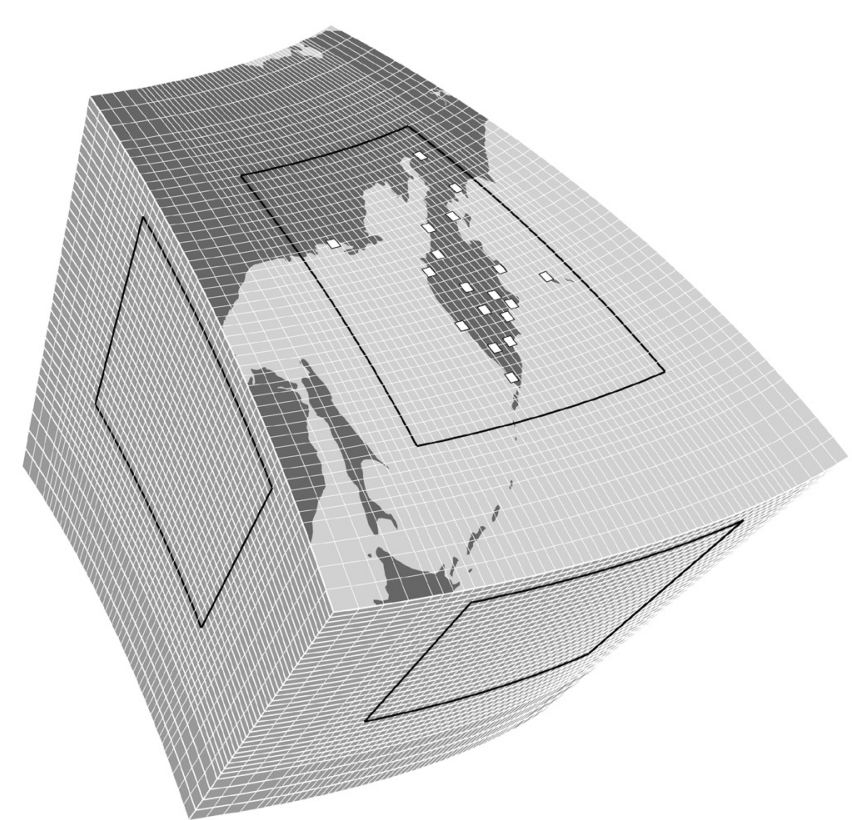

Figure 5. 3-D perspective showing the model parameterization. At the crossing point of each line, the perturbations from the 1-D background model are constrained by splines under tension, with the velocity model calculated to reduce the travel time residuals and fit the data to observations. There are 37 spline knots in the radial direction, 48 in latitude and 51 in longitude. There are a total number of 90576 nodes in the model. 
flow. Davaille and Lees [2004] suggested that side ablation via conduction alone could not completely explain the shape of the seismicity shoaling trends in northern Kamchatka. They suggested that the presence of the Meiji seamounts, remnants of the Hawaiian plume deformation of the Pacific plate, provides accelerated ablation that can account for the missing slab in the north. The model is based on small scale convection cells forming at the base of the lithosphere and carried into the subduction where they are more prone to erosion. This model, of course, cannot explain the pervasive observation around the Pacific Rim on shoaling of seismicity towards cusps in general. It is useful to keep in mind that the subduction of the Meiji seamounts may contribute to the erosion of the plate and provides an acceleration of the process of terminating the plate to the north.

While subduction was apparently active in the isthmus region of the Kamchatka Peninsula in the last 10 My we see no convincing evidence of high velocity $\mathrm{P}$-wave anomalies associated with remnant slabs in this region. This observation has been used to suggest that catastrophic failure occurred where slab remnants broke away and descended into the deep mantle [Levin et al., 2002]. Slab foundering provides a possible mechanism [Davies and von Blanckenburg, 1995] to explain upwelling thermal plumes below the Komandorsky Basin which create associated heat flow anomalies [Smirnov and Sugrobov, 1982] and volcanic geochemistry variations [Portnyagin et al., 2005]. An alternative is that a slab window opened and evolved as the Kamchatka-Aleutian junction migrated northward over time allowing thermal intrusions in the isthmus and Komandorsky regions [Dickinson and Snyder, 1979]. We suggest that observations related in this paper, especially the shoaling geometry of the slab, is common to other cusps along the Pacific rim and general explanations will have to be found that apply to all these localities to explain the phenomena. Kamchatka Peninsula is one place where a large, land based, regional array can be used to examine the subduction zone seismically. In the future, ocean bottom seismic arrays may be used to image the region between the Kamchatka subduction zone and Aleutian subduction [Levin et al., 2005]. These studies might then settle the question of how the Kamchatka-Aleutian slab window formed and evolved to its present state.

\section{CONCLUSIONS}

We conclude that teleseismic P-wave tomography clearly shows the presence of cold subducting Pacific plate slab in southern Kamchatka and an equally discernible absence of slab material subducting north of the termination of volcanism along the Kamchatka Arc. The termination of the slab to the north implies that the slab edge is exposed to the north and mantle material can flow around the edge freely. The motion of slab material around the edge of the slab causes further ablation of the slab that contaminates volcanics at the most northern active volcanoes in Kamchatka (Sheveluch) and provides an explanation for the characteristic shoaling of seismicity to the north. A low velocity anomaly beneath the region where Bering Island resides may be evidence for flow around the northern terminus of the Kamchatka subduction zone.

\section{REFERENCES}

Abers, G.A., Hydrated subducted crust at 100-250 km depth, Earth Planetary Science Letters, 176, 323-330, 2000.

Baranov, B.V., N.I. Seliverstov, A.V. Murav'ev, and E.L. Uzurov, Commander Basin: back-transform spreading, Tectonophysics, 199, 237-269, 1991.

Buttles, J., and P. Olson, A laboratory model of subduction zone anisotropy, Earth Planet. Sci. Lett., 164, 245-262, 1998.

Davaille, A., and J.M. Lees, Thermal modeling of subducted plates: tear and hot spot at the Kamchatka corner, Earth Planet. Sci. Letts., 226 (3-4), 293-304DOI:10.1016/j.epsl.2004.07.024, 2004.

Davies, J.H., and F. von Blanckenburg, Slab breakoff; a model of lithosphere detachment and its test in the magmatism and deformation of collisional orogens, Earth Planet. Sci. Letts., 129 (1-4), 85-102, 1995.

Defant, M.J., and M.S. Drummond, Derivation of some modern arc magmas by melting of young subducted lithosphere, Nature, 347, 662-665, 1990

Defant, M.J., and P. Kepzhinskas, Evidence suggests slab melting in arc magmas, Eos (Trans. AGU), 82 (6), 65-69, 2001.

Dickinson, W.R., and W.S. Snyder, Geometry of triple junctions related to San Andreas transform, J. Geophys. Res., 84, 561-572, 1979.

Gaedicke, C., B. Baranov, N. Seliverstov, A. Alexeiev, N. Tsukanov, and R. Freitag, Structure of an active arc-continent collision area: The Aleutian-Kamchatka junction, Tectonophys., 325, 63-85, 2000.

Geist, E.L., and D.W. Scholl, Large-scale deformation related to the collision of the Aleutian arc with Kamchatka, Tectonics, 13 (2), 538-560, 1994.

Gorbatov, A., J. Dominguez, G. Suarez, V. Kostaglodov, D. Zhao, and E. Gordeev, Tomographic imaging of $\mathrm{P}$ wave velocity structure beneath Kamchatka Peninsula, Geophys. J. Int., 137, 269-279, 1999.

Gorbatov, A., V. Kostoglodov, S. Gerardo, and E. Gordeev, Seismicity and structure of the Kamchatka subduction zone, $J$. Geophys. Res., 102, 17883-17898, 1997.

Gorbatov, A., A. Widiyantoro, Y. Fukao, and E. Gordeev, Signature of remnant slabs in the North Pacific from P-wave tomography, Geophys. J. Int., 142, 27-36, 2000.

Hochstaedter, A.G., P.K. Kepezhinskas, M.J. Defant, M.S. Drummond, and $\mathrm{H}$. Bellon, On the tectonic significance of arc volcanism in northern Kamchatka, J. Geol., 102, 639-654, 1994.

Kennett, B.L.N., and E.R. Engdahl, Travel times for global earthquake location and phase identification, Geophys. J. Int., 105, 429-465, 1991. 
Kirby, S.H., E.R. Engdahl, and R.P. Denlinger, Intermediate-depth intraslab earthquakes and arc volcanism as physical expressions of crustal and uppermost mantle metamorphism in subducting slabs, in Subduction top to bottom, edited by G.E. Bebout, D.W. Scholl, S.H. Kirby, and J.P. Platt, pp. 195-214, 1996.

Lees, J.M., Implications of slab tear on geodynamics, seismology and volcano geochemistry, in Eos (Trans. AGU), pp. 1080, 2000.

Lees, J.M., M. Brandon, J. Park, V. Levin, A. Ozerov, and E. Gordeev, Kamchatka: Edge of the Plate, Iris News Letter, 2000 (1), 17-19, 2000.

Levin, V., D. Droznin, J. Park, and E. Gordeev, Mantle wedge anisotropy beneath southeastern Kamchatka from local-S birefringence, Geophys J. Int., 158, 1009-1023, 2004.

Levin, V., N. Shapiro, J. Park, and M. Ritzwoller, Seismic evidence for catastrophic slab loss beneath Kamchatka, Nature, 418, 763-767, 2002.

Levin, V., N. Shapiro, J. Park, and M. Ritzwoller, Slab Portal beneath the western Aleutians, Geology, 33 (4), 253-256, 2005.

Moore, G.W., N.A. Bogdanov, K.J. Drummond, X. Golovchenko, R.L. Larson, W.C. Pitman, III, W.A. Rinehart, L. Siebert, T. Simkin, S.M. Tilman, and S. Uyeda, Plate-tectonic map of the Circum-Pacific Region, Arctic Sheet, in Circum-Pacific Map Series, pp. 20, United States Geological Survey, 1992.

Nokleberg, W.J., L.M. Parfenov, J.W.H. Monger, I.O. Norton, A.I. Khanchuk, D.B. Stone, C.R. Scotese, D.W. Scholl, and K. Fujita, Phanerozoic Tectonic Evolution of the Circum-North Pacific, 122 pp., 2001.

Park, J., V. Levin, M.T. Brandon, J.M. Lees, V. Peyton, E. Gordeev, and A. Ozerov, A dangling slab, amplified arc volcanism, mantle flow and seismic anisotropy near the Kamchatka plate corner, in Plate Boundary Zones, edited by S. Stein and J. Freymueller, pp. 295-324, AGU, Washington DC, 2002.

Peyton, V., V. Levin, J. Park, M. Brandon, J. Lees, E. Gordeev, and A. Ozerov, Mantle Flow at a Slab Edge: Seismic Anisotropy in the Kamchatka Region, Geophys. Res. Lett., 28 (2), 379-382, 2001.

Portnyagin, M., K. Hoernle, G. Avdeiko, F. Hauff, R. Werner, I. Bindeman, V. Uspensky, and D. Garbe-Schönberg, Transition from arc to oceanic magmatism at the Kamchatka-Aleutian junction, Geology, 33 (1), 25-28DOI:10.1130/G20853.1, 2005.
Russo, R.M., and J.M. Lees, Seismic Anisotropy beneath Pacific Ocean Lithosphere Subducted at Kamchatka, submitted to Journal of Geophysical Research-Solid Earth, 2005.

Russo, R.M., and P.G. Silver, Trench-parallel flow beneath the Nazca Plate from seismic anisotropy, Science, 263, 1105-1111, 1994.

Seliverstov, N.I., Structure of Kamchatkian Water Area Bottom and Geodynamic of a Junction Zone between the Kuril-Kamchatka and Aleutian Island Arcs (in Russian), 164 pp., Nauchnyi Mir, Moscow, 1998.

Smirnov, Y.B., and Y.M. Sugrobov, Terrestrial heat flow in the Northwestern Pacific, Tectonophysics, 83, 109-122, 1982.

VanDecar, J.C., and R.S. Crosson, Determination of teleseismic relative phase arrival times using multi-channel cross correlation and least squares, Bull. Seis. Soc. Am., 80 (1), 150-169, 1990.

VanDecar, J.C., R.M. Russo, D.E. James, W.B. Ambeh, and M. Franke, Aseismic continuation of the Lesser Antilles slab beneath continental South America, J. Geophys. Res., 108, 2043DOI:10.1029/2001JB000884, 2003.

Yogodzinski, G.M., J.M. Lees, T.G. Churikova, F. Dorendorf, G. Woerner, and O.N. Volynets, Geochemical evidence for the melting of subducting oceanic lithosphere at plate edges, Nature, 409, 500-504, 2001.

Jonathan M. Lees, University of North Carolina, Chapel Hill, Department of Geological Sciences, CB\#3315, Mitchell Hall, Chapel Hill, NC 27599-3315

John VanDecar, Department of Terrestrial Magnetism, Carnegie Institution of Washington, 5241 Broad Branch Rd., NW, Washington, DC 20015

Evgenii Gordeev and Alexei Ozerov, Institute of Volcanology and Seismology (IVS), Petropavlovsk-Kamchatsky, Piip Boulevard 9, 683006, Russia

Mark Brandon, Yale University, P.O. Box 208109, 210 Whitney Avenue, New Haven, CT 06520-8109

Jeff Park, Yale University, P.O. Box 208109, 210 Whitney Avenue, New Haven, CT 06520-8109

Vadim Levin, Department of Geological Sciences, Rutgers University, 610 Taylor Road, Piscataway, New Jersey 08854 8066 
